\title{
A PROPOSTA DE CRIAÇÃO DO FUNDEB E SUA RELAÇAO COM OS ESTUDOS SOBRE OS IMPACTOS DO FUNDEF NA EDUCAÇÃO DO ESTADO DO PARÁ
}

\section{Rosana Gemaque ${ }^{1}$}

Resumo

O texto analisa alguns indicadores do processo de elaboração do Fundo de Manutenção e Desenvolvimento da Educação Básica e de Valorização dos Profissionais da Educação (FUNDEB), na perspectiva de verificar em que medida os impactos do Fundo de Manutenção e Desenvolvimento do Ensino Fundamental e de Valorização do Magistério (FUNDEF) na educação - identificados em estudos -, estão sendo considerados na elaboração do novo Fundo. Para isso, toma por referência o estudo de caso realizado no Estado do Pará e alguns resultados de estudos realizados no Estado da Bahia, Paraíba e São Paulo, os quais apontam os limites do FUNDEF como política capaz de combater às desigualdades educacionais regionais e de melhorar a qualidade do ensino. A análise do processo de elaboração do FUNDEB revela que, apesar dos vários estudos produzidos sobre os impactos do FUNDEF em vários Estados e municípios, as principais discussões e encaminhamentos em torno da elaboração do referido Fundo estão desconsiderando os resultados de estudos e a luta política continua sendo tal como se efetivou no processo de elaboração do FUNDEF: disputa em torno de perdas e ganhos de recursos financeiros entre a União, Estados e municípios. O combate às desigualdades educacionais e a melhoria da qualidade de ensino continuam sendo desconsiderados na discussão.

Palavras-chave: Financiamento, Educação, FUNDEB.

Abstract

This article analyses some indicators about the process of elaboration to Fund for the Maintenance and Development of Basic School and the Valorization of Primary School Teaching (FUNDEB), in the perspective the exam of the effects of the Fund for the Maintenance and Development of Primary School Education and the Valorization of Primary School Teaching (FUNDEF) - recognized in others studies had been considerate in the elaboration of the new fund. For this, had taken a reference the work of case in Pará State and some results of studies at Bahia, Paraíba and São Paulo. These studies indicate the limits of FUNDEF how politic appears capable of abolish regional inequality education and improve the quality education. The analyses of the elaboration process showed, nevertheless the production of many studies about FUNDEF effects in the states and municipal governments, all mean discussions and conduct about the FUNDEB had disregarded all studies. The politic fight remaining some the process of FUNDEF elaboration: dispute of profit and loss of recourses between Federal, State and Municipal government. The combat of inequalities education and improve the quality education going on disregard.

Key-words: Financing, Education, FUNDEB.

\section{Introdução}

Independente das controvérsias a respeito da intenção política que norteou a constituição do Fundo de Manutenção e Desenvolvimento do Ensino Fundamental e de Valorização do Magistério - Fundef e das possibilidades de impacto desse fundo, tratase de uma política que revigorou os estudos, debates e pesquisas na área de financiamento da educação, dentro e fora da academia, evidenciado pelo número considerável de publicações e trabalhos apresentados em eventos da área sobre essa temática. Além disso, estimulou a constituição e fortalecimento de grupos de pesquisadores na área em âmbito nacional que reúnem informações consideráveis sobre

\footnotetext{
${ }^{1}$ Professor da Universidade Federal do Pará. E-mail: rgemaque@ uol.com.br.
} 
os efeitos dessa política e seus limites para combater as desigualdades educacionais e melhorar a qualidade de ensino no País.

Diante disso questionamos: até que ponto os resultados de estudos realizados sobre os impactos do Fundef estão sendo considerados no processo de criação do Fundo de Manutenção e Desenvolvimento da Educação Básica e de Valorização dos Trabalhadores em Educação - Fundeb?

Nessa perspectiva, o texto analisa o processo de elaboração do Fundeb com o objetivo de verificar a relação entre a produção do conhecimento na educação e a definição/elaboração de políticas públicas educacionais. Para isso, considera quatro estudos que avaliam impactos do Fundef nos estados do Pará, Bahia, Paraíba e São Paulo e elege como indicadores de análise as desigualdades educacionais regionais e melhorias na qualidade do ensino

Os referidos estudos consistem: a) na tese de doutorado desenvolvida por GEMAQUE (2004), intitulada "Financiamento da Educação. O Fundef no Estado do Pará: feitos e fetiches"; b) na tese de doutorado de BASSI (2001), "Gestão e financiamento da educação básica"; na tese de doutorado de SOUZA JR. (2003), "Financiamento e Educação. Os impactos do Fundef na Educação Básica da Paraíba"; e no estudo realizado por VERHINE e outros (2003), "Fundef no Estado da Bahia", publicado na revista Gestão em Ação.

Com a intenção de explicitar os referenciais e argumentos desenvolvidos, o texto está assim organizado: a) Informações gerais sobre o Fundef; b) Impactos do Fundef na educação do estado do Pará, São Paulo, Bahia e Paraíba; c) Processo e proposta de criação do Fundeb; d) Considerações finais

\section{Informações gerais sobre o Fundef}

Em documento apresentado no Seminário "Desigualdade e Pobreza no Brasil", realizado pelo Instituto de Pesquisa Econômica Aplicada (IPEA), em 1999, foi ressaltado que as desigualdades regionais no Sistema Educacional Brasileiro suscitaram preocupações ao Governo Fernando Henrique Cardoso, expressas nas políticas implementadas pelo Ministério da Educação (MEC), a partir de 1995. Foi também enfatizado que, a despeito da melhoria dos indicadores educacionais na última década, o grau de desigualdade regional e interestadual foi se aprofundando, especialmente em relação aos indicadores de "transição", "eficiência" e "efetividade" do sistema, sendo constatado que o único indicador praticamente universalizado nos últimos três anos da 
série analisada (1989-1998) foi o acesso ao Ensino Fundamental, mas que em relação ao grau de aprendizagem continuou se delineando "um quadro de profundas desigualdades regionais, algumas até mais acentuadas que o quadro observado no início da década de 80", mesmo com tendências de melhoria sistemática evidenciada na segunda metade da década de 90 (CASTRO, 1999, p. 1 e 20).

Nesse contexto, o Fundef foi destacado, no referido documento, como a estratégia mais importante implementada pelo MEC, com a "intenção" de combater as desigualdades educacionais regionais.

Em vários documentos oficiais é reafirmada a idéia de que o Fundef foi criado com a finalidade de corrigir as "iniqüidades históricas que impediam o desenvolvimento do sistema educacional e tolhiam o futuro de muitos brasileiros", considerando que a má distribuição dos recursos da educação constituía-se "raiz das desigualdades existentes nas redes públicas de ensino em todo País" (MEC, 1999).

O Fundef foi criado pela Emenda Constitucional $N^{\circ} 14$, de 12/09/1996, e regulamentado pela lei federal $\mathrm{N}^{\circ}$ 9.424, de 24/12/1996. É composto por $15 \%$ dos recursos provenientes de ICMS, FPE, FPM, IPI/EXPO e dos recursos transferidos a título de compensação financeira pela perda de receitas decorrentes da desoneração das exportações. Os valores arrecadados deverão ser distribuídos proporcionalmente ao número de alunos matriculados nas redes de ensino dos Estados e de seus municípios. Caso o valor mínimo a ser gasto por aluno não seja alcançado nos estados e municípios, a União participa na condição de complementar os recursos.

Do montante arrecadado, 60\% são destinados ao pagamento de professores do ensino fundamental, em efetivo exercício no magistério, e os $40 \%$ restantes deverão ser aplicados na manutenção e desenvolvimento desse mesmo nível de ensino.

Desta feita, o Fundef movimenta receitas dos estados, do Distrito Federal, dos municípios e, em alguns casos, da União. Essa participação dos entes federados é obrigatória, automática e incide sobre as receitas próprias (estados) e transferidas constitucionalmente, já vinculadas à educação. Por isto, não gera novos recursos para o ensino fundamental, salvo nos estados em que há complementação da União, ou seja, tão-somente os redistribui no âmbito de cada estado. Tal suplementação não significa nova fonte de recursos, mas simplesmente retira dos já existentes (da receita de impostos e do salário-educação).

Portanto, a natureza e a configuração do Fundef o caracterizam como um fundo de gestão, porque sua dinâmica consiste, num primeiro momento, na centralização dos 
recursos, para depois redistribuí-los na proporção do número de matrículas existentes nas respectivas redes de ensino. A sua estrutura não visa à ampliação dos recursos, mas à focalização na sua aplicação. Não se trata de um fundo canalizador de novos recursos, mas de gerenciamento, cuja tarefa foi concedida à União que o criou e o gerencia. Esta medida é interpretada por alguns advogados e juízes como inconstitucional, por ferir os princípios do federalismo, no que concerne à intervenção da União na autonomia financeira dos estados e municípios, na aplicação dos seus recursos. Além disso, a União ainda ficou com a atribuição de definir o valor mínimo que funciona como um piso de investimento do poder público para o ensino fundamental, complementando-o naquele estado em que esse valor não for atingido.

Ressalta-se que somente a partir de 2000, ou seja, dois anos após a implantação automática do fundo, a lei foi obedecida pela União, no que concerne à definiçãa do valor do custo-aluno-ano, diferenciada por tipo de ensino, com percentual correspondente a $5 \%$ entre os alunos de $1^{\mathrm{a}}$ a $4^{\mathrm{a}}$ séries, de $5^{\mathrm{a}}$ a $8^{\mathrm{a}}$ séries e de educação especial (a partir de 2005 foram consideradas diferentemente: séries iniciais urbanas, séries inicias rurais; 4 séries finais urbanas; e 4 séries finais rurais e educação especial). Entretanto, os valores diferenciais não foram, conforme consta no relatório do grupo de trabalho para estudo do valor mínimo do Fundef-2003, “respaldados por um necessário e criterioso estudo de custos que pudesse justificá-lo, mesmo tendo sido adotado somente a partir de 2000” (MEC, 2003, p.6). Além disso, até hoje, a Lei não foi cumprida em relação à diferenciação por tipo de estabelecimento de ensino e à estimativa de novas matrículas.

Estudos realizados por GEMAQUE (2004) revelam que, de 1997 a 2000, as matrículas do ensino fundamental regular no Brasil foram ampliadas em 2.056.863, o que correspondeu, em valores relativos, a 7,0\% e a uma média anual de 2,3\%. Índice previsível, tendo em vista que o atendimento na faixa etária de 7 a 14 anos já estava praticamente universalizado, o que também contribuiu para a redução da suplementação da União para os fundos estaduais. No entanto, a situação poderia ser bem diferente se não houvesse o veto das matrículas do ensino supletivo, onde a demanda é bem superior.

De 1998/2001, o valor total do fundo aumentou, em valores nominais, em $51,4 \%$. Considerando os valores do fundo sem a complementação da União, o aumento foi de $53,2 \%$. Isto indica que o crescimento se deveu às contribuições dos estados e municípios, visto que a complementação da União foi reduzida em 4,0\%, nesse período. 
Entretanto, ao considerarmos os valores reais (corrigidos a preço de maio/2002- IGPDI), o crescimento do valor total do fundo foi apenas de $8,3 \%$ e a complementação da União para os estados foi reduzida em $31,2 \%$.

Quanto à complementação da União para os estados, vale destacar que, em 1998, ano de implantação automática do fundo, os estados contemplados foram oito: Alagoas, Bahia, Ceará, Maranhão, Pará, Paraíba, Pernambuco e Piauí. Dentre eles, o estado da Bahia foi o que recebeu maior suplementação, seguido pelo Maranhão e o Pará. Em 2001, o número de estados contemplados foi reduzido para quatro, deixando de receberem os estados de Pernambuco, Paraíba, Ceará e Alagoas. Conforme consta nos Boletins do Fundef, referentes ao ano de 2001, estes dois últimos ainda receberam complementação até agosto. Porém, no ano seguinte quando a União fez a contabilização, os valores repassados foram considerados indevidos (Boletim-Ano V, $\mathrm{n}^{\circ}$ 08-agosto/2002). Desta feita, não houve complementação.

No que se refere à participação percentual de contribuição para a composição do Fundef, por esfera de governo, foi constatado que, enquanto os estados e municípios contribuíram com aproximadamente $98,0 \%$ do total, a participação da União foi de $2 \%$, entre 1998/2001. Ou seja, os principais acionistas desse fundo são os governos subnacionais, o que expõe a contradição entre o discurso e a prática do governo federal, no que concerne à prioridade ao ensino obrigatório - a menos que essa exigência seja somente para os Estados e municípios.

Em relação à média dos valores per capita/Fundef, os estudos realizados por GEMAQUE (2004) mostram que, em 1998, o estado que apresentou o menor valor médio per capita/Fundef foi o Maranhão, que continuou ocupando a mesma posição em 2001, apesar de ter apresentado crescimento real de 27,0\% (não foi considerado o valor do Distrito Federal pelo fato de não haver informações sobre o repasse do ICMS). De outro lado, o estado que apresentou o maior valor médio per capita foi o de Roraima, que também permaneceu na mesma condição em 2001. Entretanto, em valores reais, o per capita desse estado foi reduzido em 6,2\% de 1998 a 2001. Apesar disso, não houve redução da diferença dos per capita entre os estados "ricos" e "pobres". Em 1998, a diferença entre a média do maior e menor valor foi de $\mathrm{R} \$ 2.000,00$ e, em 2001, essa diferença aumentou para $\mathrm{R} \$ 2.316,00$. Ressalva-se que esse resultado contradiz o argumento justificador da implementação dessa política: reduzir as disparidades entre o custo-aluno, conformando-se, desta feita, a previsão inicial sobre os resultados desse fundo que, nos moldes como foi organizado, não diminuiria as disparidades, mas 
tenderia a cristalizá-las ou mesmo ampliá-las (MELCHIOR, 1997), visto que a magnitude dos recursos mobilizados nos estados depende da arrecadação do ICMS e das transferências do FPE e FPM. Nos estados do Sudeste e do Sul, a arrecadação do ICMS é expressivamente maior que a dos estados do Norte e Nordeste e os bons índices apresentados por Roraima, Acre e Amapá se devem à forma de redistribuição do FPE, adotada desde 1989.

Outra informação apresentada por GEMAQUE (2004), diz respeito ao crescimento das matrículas do ensino fundamental, que nos estados ricos foi bem inferior ao crescimento evidenciado nos estados pobres, qual seja: 1,3\% e de $16,5 \%$, respectivamente. Apesar disso, as desigualdades aumentaram, revelando o limite desse tipo de política, cuja intenção principal não foi e continua não sendo essa. Caso contrário, a natureza e características do fundo seriam outras.

Todavia, se a Lei fosse cumprida pelo governo Federal, esse quadro poderia ser mais promissor, mas, ele foi o primeiro a desrespeitá-la.

A regulamentação do Fundef, com base na Lei $n^{\circ} 9.424 / 96$, prevê no seu art. $6^{\circ}$ :

$\S 1^{\circ} \mathrm{O}$ valor mínimo anual, por aluno, ressalvado o disposto no $\S 4^{\circ}$, será fixado por ato do Presidente da República e nunca será inferior à razão entre a previsão da receita total para o Fundo e a matrícula total do Ensino Fundamental no ano anterior, acrescida do total estimado de novas matrículas, observado o disposto no art. $2^{\circ}, \S 1^{\circ}$, inciso I.

Entretanto, a interpretação que o MEC fez do $\$ 1^{\circ}$ do art. $6^{\circ}$ no governo $\mathrm{FHC}$ e continuou fazendo no governo Lula, diferencia-se bastante da feita pelo TCU, pela UNDIME, CNTE, CONSED e outros. A interpretação do MEC, que contribui sobremaneira para a redução da complementação da União ao Fundef, é a de que o cálculo do valor mínimo por aluno deve levar em conta a receita total do Fundef e as matrículas efetivadas no Ensino Fundamental em cada estado, isoladamente, por se tratar de um fundo estadual. Isso resultará em 27 per capita distintos. Desta feita, a definição do valor mínimo deve encontrar-se no intervalo entre a maior e menor média do valor per capita, alcançado pelos estados, que foram os de Roraima e do Maranhão. A outra interpretação parte do pressuposto de que a definição do valor mínimo deve considerar a receita total do Fundef e o número de matrículas de todos os estados e do Distrito Federal conjuntamente. Deste modo, o valor médio resultante deve ser o parâmetro para definir o valor mínimo nacional, que não deve ser inferior a essa média (Relatório do Grupo de Trabalho-Estudo do Valor Mínimo do Fundef-2003). 
Cada interpretação resultará num valor diferente do per capita mínimo. Desta feita, foi observado por GEMAQUE (2004) que, em termos nominais, o valor per capita mínimo definido pelo Presidente da República para $1^{\mathrm{a}}$ à $4^{\mathrm{a}}$ séries cresceu em $15,2 \%$, de 1998/2001 e para $5^{\text {a à }} 8^{\text {a }}$ séries e educação especial, em 21,0\%. Entretanto, em valores reais, foram reduzidos em 17,6\% e 13,4\%, respectivamente, ou seja, além da União estabelecer o valor mínimo à revelia da lei, os reajustes anuais não chegaram a acompanhar a inflação do período. Caso a União tivesse obedecido à lei no cálculo do investimento mínimo por aluno, a situação teria sido um pouco diferente: o per capita de $1^{\mathrm{a}}$ a $4^{\mathrm{a}}$ séries sofreria uma redução de $0,6 \%$ e o de $5^{\mathrm{a}}$ a $8^{\mathrm{a}}$ séries e educação especial, aumentaria em $4,5 \%$ (valor real).

Em relação à suplementação da União para o fundo, caso a lei fosse cumprida, os valores aumentariam significativamente, nesse mesmo período. Neste caso, ao invés de 8 estados contemplados em 1998, teríamos 17; e, em 2001, ao invés de 4, teríamos 15. Desta feita, a dívida da União para o Fundef, no período $1998 / 2001$, foi de $R \$ 7,3$ bilhões, em valores nominais; e de R \$ 9,2 bilhões, em valores reais. É o mesmo que dizer a União conseguiu, com essa interpretação subjetiva do $\S 6^{\circ}$ da Lei $n^{0} 9.424$, economizar cerca de $\mathrm{R} \$$ 9,2 bilhões, contribuindo com isso para aumentar o superávit primário e garantir recursos para o pagamento da dívida externa.

\section{Impactos do Fundef na educação dos estados do Pára, São Paulo, Bahia e Paraíba.}

Registram-se vários estudos realizados e em realização em programas de PósGraduação sobre as repercussões e impactos do Fundef em Estados e municípios.

Sobre o caso de São Paulo, a tese de doutorado de Marcos BASSI (PUC-SP, 2001), apresenta questões referentes à gestão e ao financiamento da educação básica, sob a ótica do Fundef, em sete municípios paulistas. A análise de BASSI centrou-se nos dados empíricos, coletados em uma pesquisa, sob sua coordenação, patrocinada pela Ação Educativa. O período focalizado foi de 1994 e 1998 e envolveu os municípios de Aguaí, Alfredo Marcondes, Cubatão, Descalvado, Diadema, Itatiba e São Paulo.

O objetivo do autor foi investigar as repercussões do efeito financeiro do Fundef nos diferentes níveis/modalidades de ensino da rede municipal de educação, enfatizando as matrículas, o gasto-aluno, o orçamento municipal diante das restrições financeiras impostas pelo Fundef. Dentre as conclusões, ressaltam-se: a) no estado de São Paulo, o Fundef desencadeou um intenso processo de municipalização do ensino, acompanhado de um conjunto de medidas que emergiram da política educacional do 
governo estadual, sendo que a engenharia operacional do fundo favoreceu financeiramente esse nível de governo; a prioridade ao ensino fundamental repercutiu de forma negativa na oferta da educação infantil em alguns dos municípios da amostra; permaneceram grandes discrepâncias nos valores de gasto por aluno na manutenção dos mesmos serviços educacionais.

Por fim, BASSI aponta alguns dos problemas que acompanham a política do Fundef, dentre eles: o tratamento homogêneo para realidades municipais muito diferenciadas. Diante disto, alerta para o alcance tímido de programas com as características do Fundef, embora reconhecendo que possibilita o "uso mais eficiente dos recursos financeiros disponíveis e faz avançar a eqüidade do gasto por aluno". Avalia que o mérito desse fundo reside na sua contribuição para a universalização "definitiva" do ensino fundamental, entretanto, comenta "esse movimento e o emprego dos recursos públicos não são suficientes para alterar os baixos padrões de qualidade do ensino público, além de relegar a segundo plano o atendimento aos outros níveis da educação básica" (BASSI, 2001, p.202).

Outro estudo merecedor de destaque, diz respeito à pesquisa desenvolvida, em rede nacional, por vários professores vinculados a universidades, sobre o "Processo de Implantação e Impacto do Fundef em estados e municípios: casos e comparações com vista a uma avaliação”. O objetivo principal foi descrever e analisar a implantação do Fundef em alguns Estados e municípios brasileiros e avaliar seu impacto sobre a manutenção e desenvolvimento do ensino. A amostra foi formada por 12 estados e 72 municípios.

Os resultados do estudo realizado pelo Grupo da Bahia, sob a coordenação do professor Robert E. VERHINE (2003), revelam que, nesse estado, o Fundef apresentou um impacto de natureza mista nos três primeiros anos de funcionamento, com tendências em prol da municipalização e da universalização do ensino fundamental. A grande maioria dos municípios recebeu complementação do fundo para além dos recursos enviados, mas não foi confirmado se esses ganhos relativos produziram ensino de qualidade ou se possibilitaram maior eqüidade entre os municípios, em relação ao compromisso financeiro com o ensino público. Situação também observada nos estudos de caso realizados em 5 municípios, que sinalizaram a realização de algumas mudanças positivas com a implantação do Fundef, mas, ao mesmo tempo, indicaram que os resultados alcançados, no seu conjunto, têm sido aquém do esperado. Registra também que "com o Fundef, os municípios estudados passaram a assumir um papel de maior 
destaque na oferta dos serviços educacionais, responsabilizando-se pela Educação Infantil, ainda de forma limitada, e por uma parte significativa do Ensino Fundamental" (VERHINE, 2003, p.116).

O estudo realizado por Luiz de SOUZA JUNIOR (2003) sobre os impactos do Fundef na educação básica do estado da Paraíba (tese de doutorado - USP e também vinculado ao Grupo Nacional de Pesquisa) apresenta questões referentes à gestão financeira e educacional no âmbito do estado e de quatro municípios, buscando averiguar se houve relação causal entre a nova modalidade financeira redefinida pelo Fundef e os resultados obtidos, de 1996 a 2000, referentes: à universalização do ensino fundamental e à sua melhoria; aos reflexos nos demais níveis de ensino da educação básica. Além disso, procurou verificar em que medida os resultados perseguidos pela política do Fundef estão sendo alcançados satisfatoriamente.

Dentre as conclusões ressaltam-se: o resultado dessa política de financiamento da educação tem acentuado as desigualdades no que se refere ao ensino nacional, constatado tanto na rede estadual quanto nas quatro redes municipais de ensino do estado da Paraíba; o Fundef tem sido custeado quase na totalidade pelas receitas do próprio estado e de seus municípios, evidenciando que a política da eqüidade tem um sentido unilateral; o estado e alguns municípios pesquisados realizaram um movimento contábil de transferência dos gastos da educação infantil e do ensino médio para o programa ensino fundamental, inflacionando e comprometendo os resultados do Fundef; esse fundo foi responsável por uma nova onda de municipalização das matrículas; houve extinção das matrículas das classes de alfabetização e transferências dos alunos dessas classes, da pré-escola e da educação de jovens e adultos para o ensino fundamental; as matrículas da educação infantil foram reduzidas; os impactos do Fundef foram maiores nos municípios mais pobres que sobrevivem das transferências, sobre as quais o fundo incide; houve melhorias nas condições de trabalho docente, tanto em relação à questão salarial quanto à formação inicial.

Outro estudo que serve de referência para as discussões deste texto é o de GEMAQUE (2004) (tese de doutorado realizada junto ao Programa de Pós-Graduação da Faculdade de Educação da USP). Trata-se de uma pesquisa que avaliou impactos do Fundef na educação do estado do Pará, especificamente no Sistema Estadual de Educação, no Sistema de Ensino do Município de Belém e na Rede de Ensino do Município de Santarém. Seu objetivo foi avaliar a pertinência do arranjo financeiro criado com esse fundo, considerando: (i) as disparidades do gasto-aluno intra-estadual; 
(ii) a capacidade de atendimento educacional dos municípios; (iii) a focalização dos recursos; (iv) e a cooperação entre as esferas de governo no provimento do ensino fundamental. Para isso, foi analisada a magnitude dos recursos totais e adicionais mobilizados por esse fundo, observando a sua redistribuição e efeitos nas receitas, na gestão e no valor per capita.

A análise dos dados foi orientada pelos princípios e objetivos do Fundef, questionando os procedimentos adotados na sua formulação e implementação, os atores envolvidos e a sua configuração final. Os impactos/efeitos foram identificados e avaliados a partir do percentual de variação das informações referentes aos anos de 1996 a 2001 e da visão dos sujeitos mais diretamente envolvidos (Secretários de Educação, de Finanças, Conselheiros do Fundef, diretores e professores).

Foi constatado que, no Pará, houve considerável redistribuição de recursos do governo do estado para os municípios, possibilitando a ampliação do gasto por aluno do Ensino Fundamental e a redução da diferença entre o maior e menor per capita. Entretanto, o resultado interno em nada alterou o quadro externo: o per capita do Pará continuou sendo um dos menores do país, tendo em vista que o principal acionista do fundo paraense é o próprio governo do estado. Além disso, houve redução das matrículas na educação infantil e as do ensino médio não foram ampliadas na mesma proporção que o governo estadual repassou as do ensino fundamental para os municípios, resultando na redução do atendimento à educação básica e dos gastos efetivados por esse governo. Desta feita, concluiu-se que o Fundef vem colaborando mais para racionalizar os recursos da União e do governo do estado do Pará, através da municipalização do ensino fundamental, do que para equalizar o gasto-aluno em nível nacional, tendo em vista que a diferença entre os per capita dos estados ricos e pobres foi ampliada, no período do estudo.

Por fim, os resultados desses estudos revelam impactos do Fundef em várias perspectivas e dimensões, servindo como indicadores ou parâmetros de análise para avaliar impactos da atual política de financiamento da educação pública no Brasil e as perspectivas de melhorias com a criação do Fundeb.

Nessa perspectiva, analisamos a proposta de criação do Fundeb, chamando a atenção para a relação e considerações sobre os resultados desses estudos e as possibilidades dessa nova proposta de fundo superar os limites do Fundef no que concerne ao combate às desigualdades educacionais e as possibilidades de melhorar a qualidade do ensino. 


\section{Processo e proposta de criação do Fundeb}

No Congresso Nacional, até 2004, tramitavam oito propostas de emendas à Constituição com a finalidade de alterar o financiamento da educação. Entre elas, duas destinavam-se a substituição do Fundef pelo Fundeb (PEC n. 112/99 e a PEC n.34/2002). As demais tratavam da distribuição do salário educação, da prorrogação do Fundef para 2016 e outras da criação de fundos próprios para a educação infantil e para o ensino médio.

Em 2005, com a chegada ao Congresso Nacional da PEC-415/05, todas foram apensadas à PEC № 536/97.

Vale lembrar que o Fundeb estava previsto no programa de governo de Lula na perspectiva de assegurar uma política de inclusão no âmbito de toda a educação básica. As propostas para a educação do governo Lula encontram-se sistematizadas em um documento intitulado "Uma Escola do tamanho do Brasil".

No referido programa, a educação, em todos os níveis, foi concebida como um direito social básico e universal, sendo considerada "vital para romper com a história de dependência científica, tecnológica e cultural e para a construção de uma nação autônoma, soberana e solidária consigo mesma e com outras nações". Além disso foi enfatizado que: "a expansão do sistema educacional público e gratuito e a elevação de seus níveis de qualidade são prioridades do novo modelo de desenvolvimento social a ser implementado no governo Lula" (PARTIDO DOS TRABALHADORES, 2002, p. 2).

No que concerne à política de financiamento da educação para a educação básica, a criação do Fundeb em substituição ao Fundef foi considerado o carro-chefe do atual governo.

$\mathrm{Na}$ visão do executivo, os objetivos do Fundeb visam: (i) promover a equalização, pela distribuição de recursos da educação entre os estados e seus municípios; (ii) universalizar o atendimento na educação básica (exceto creche); (iii) reduzir desigualdades, com garantia de investimento mínimo que assegure qualidade do ensino; (iv) valorizar os profissionais da educação; (v) assegurar as condições de garantia de piso-salarial nacional para o magistério.

No Ministério da Educação foi constituído um grupo de trabalho para aprofundar os estudos sobre o Fundeb e propor alterações nos projetos em tramitação, cujos resultados indicaram diretrizes para nortear a elaboração da proposta: 1) o Fundeb deve 
ser um fundo único para cada UF; 2) excluir impostos próprios dos municípios; 3) incluir 25\% de todos os impostos dos Estados e mais das transferências; 4) distribuir os recursos por matrículas da educação básica, diferenciando por etapa e modalidade; 5) excluir inativos de forma progressiva; 6) re-vincular de forma progressiva recursos da educação desvinculados (DRU); 7) distribuir do salário-educação para todas as etapas da educação básica; 8) controlar efetivo dos gastos por meio de certificação universal de freqüência e qualidade.

Aproximadamente, após um ano da divulgação dos resultados dos estudos efetivados pelo MEC, da realização de algumas audiências públicas e de colóquios em alguns estados (Rio Grande do Sul; São Paulo; Minas Gerais; Piauí; Tocantins; Distrito Federal) e também da apresentação de propostas de algumas entidades como a União Nacional dos Dirigentes Municipais de Educação - UNDIME, do Conselho Nacional de Secretários Estaduais de Educação - CONSED, da Confederação Nacional dos Trabalhadores em Educação - CNTE, o Executivo encaminhou ao Congresso uma proposta de Emenda à Constituição, codificada como PEC No 415/05.

Ressalta-se: a análise das sínteses dos referidos colóquios revela que, embora em alguns, a discussão sobre o combate às desigualdades educacionais seja mencionada, as propostas não foram expressamente fundamentadas com base em resultados de estudos realizados sobre os efeitos e impactos do Fundef em estados e municípios.

Na Câmara dos Deputados foram apresentadas cerca de trinta e seis emendas, cujas discussões mais polêmicas têm girado em torno da: exclusão/inclusão das matrículas em creche; distribuição dos recursos quanto ao percentual de matrículas a ser contemplado por etapas e modalidades de ensino; complementação da União; inclusão/exclusão de impostos municipais; utilização do salário-educação para complementar o fundo; percentagem a ser subvinculada ao fundo $(20 \%, 25 \%)$; definição do piso salarial profissional nacional; vigência do Fundo; percentagem a ser destinada à valorização do magistério, entre outros.

Em 08/12/2005, a Comissão Especial aprova parecer apresentado no Plenário e em 24/01/2006, a PEC foi aprovada em $1^{\circ}$ turno na Câmara dos Deputados e, em 02/02/2006, em $2^{\circ}$ turno.

A Tabela 1 apresenta as diferenças entre o Fundef e a proposta do Fundeb, com a intenção de subsidiar as discussões sobre a temática central do texto.

Tabela 1: Diferenças entre o Fundef e a Proposta do Fundeb 
Aprovada na Câmara dos Deputados em $1^{\circ}$ e $2^{\circ}$ turno.

\begin{tabular}{|c|c|c|}
\hline Parâmetro & Fundef & Fundeb \\
\hline Vigência & Temporária - até 2006 & Temporária - até 2019 (14 anos) \\
\hline Alcance & Ensino Fundamental & $\begin{array}{l}\text { Educação Infantil, Ensino Fundamental e Médio e } \\
\text { modalidades }\end{array}$ \\
\hline $\mathrm{N}^{\mathrm{o}}$ de Alunos & 30,7 milhões (2004) & 47,7 milhões ( a partir do $4^{\circ}$ ano) \\
\hline Montante de Recursos & $\begin{array}{l}\mathrm{R} \$ 31,2 \text { bi (previsão de 2005- sem a } \\
\text { complementação da União) }\end{array}$ & $\begin{array}{l}\text { Base } 2005-\text { sem a complementação da União: } 1^{\circ} \\
\text { ano (R } \$ 34,3 \text { bi); } 2^{\circ} \text { ano }\left(37,4 \text { bi); } 3^{\circ} \text { ano }(40,6\right. \\
\text { bi); e } 4^{\circ} \text { ano }(43,7 \text { bi) }\end{array}$ \\
\hline Fontes de Recursos & $\begin{array}{l}\text { 15\% (Estados, Distrito Federal e } \\
\text { Municípios): FPE; FPM; ICMS; IPI- } \\
\text { Exp.; Compensação decorrente da } \\
\text { desoneração das exportações; } \\
\text { complementação da União. }\end{array}$ & $\begin{array}{l}\text { Estados, DF e Municípios: (gradativamente) } \\
\text { a) FPE; FPM; ICMS; IPI-Exp, D.Exp.;: } \\
1^{\circ} \text { ano }-16,5 \% \\
2^{\circ} \text { ano }-17,50 \% \\
3^{\circ} \text { ano }-18,75 \% \\
4^{\circ} \text { ano }-20 \% \\
\text { b) ITCMD; IPVA, ITR: } \\
1^{\circ} \text { ano }-5 \% \\
2^{\circ} \text { ano }-10 \% \\
3^{\circ} \text { ano }-15 \% \\
4^{\circ} \text { ano }-20 \% \\
\text { c) Complementação da União }\end{array}$ \\
\hline $\begin{array}{l}\text { Complementação da } \\
\text { União }\end{array}$ & $\begin{array}{l}\mathrm{R} \$ 395,3 \mathrm{mi}-2005 \\
\text { Não há definição, na Constituição, } \\
\text { de parâmetro que assegure o } \\
\text { montante de recursos da União para } \\
\text { o Fundo }\end{array}$ & $\begin{array}{l}\text { Em valores de } 2005 \\
1^{\circ} \text { ano: } \mathrm{R} \$ 2,000 \mathrm{bi} \\
2^{\circ} \text { ano: } \mathrm{R} \$ 2,850 \mathrm{bi} \\
3^{\circ} \text { ano: } \mathrm{R} \$ 3,700 \mathrm{bi} \\
4^{\circ} \text { ano: } \mathrm{R} \$ 4,500 \mathrm{bi} \\
\text { A partir do } 5^{\circ} \text { ano: no mínimo, } 10 \% \text { do montante } \\
\text { do Fundo } \\
\text { No máximo, } 30 \% \text { dos } 18 \% \text { - MDE }\end{array}$ \\
\hline $\begin{array}{lll}\text { Total Geral dos } \\
\text { Recursos do Fundo }\end{array}$ & $\mathrm{R} \$ 31,6$ bi (2005) & $\begin{array}{l}1^{\circ} \text { ano: } \mathrm{R} \$ 36,2 \text { bi; } 2^{\circ} \text { ano: } \mathrm{R} \$ 40,1 \mathrm{bi} ; 3^{\circ} \text { ano: } \mathrm{R} \$ \\
44,1 \mathrm{bi} ; 4^{\circ} \text { ano: } \mathrm{R} \$ 48,0 \text { bi }\end{array}$ \\
\hline $\begin{array}{l}\text { Distribuição } \quad \text { dos } \\
\text { Recursos }\end{array}$ & $\begin{array}{l}\text { Com base no número de alunos } \\
\text { matriculados no ensino fundamental } \\
\text { regular e especial (Censo escolar do } \\
\text { ano anterior) }\end{array}$ & $\begin{array}{l}\text { Com base no } \mathrm{n}^{\circ} \text { de alunos da educação básica } \\
\text { (creches; pré-escolar; fundamental e médio) } \\
\text { registrado no censo escolar do ano anterior, a } \\
\text { partir da escola de inclusão: } \\
\text { 1) Ens.Fundamental regular e especial: } \\
100 \% \text {, a partir do } 1^{\circ} \text { ano; } \\
\text { 2) Educação Infantil, Ensino Médio e EJA: } \\
25 \%\left(1^{\circ} \text { ano); } 50 \%\left(2^{\circ} \text { ano); } 75 \% \text { ( } 3^{\circ}\right.\right. \\
\text { ano); e } 100 \% \text { (a partir do } 4^{\circ} \text { ano); } \\
\text { Prioridade de atendimento por esfera de governo } \\
\text { (estadual e municipal). }\end{array}$ \\
\hline Utilização dos recursos & $\begin{array}{l}\text { Mínimo de } 60 \% \text { para a remuneração } \\
\text { dos profissionais do magistério; } \\
\text { O restante dos recursos em outras } \\
\text { despesas do ensino fundamental } \\
\text { público }\end{array}$ & $\begin{array}{l}\text { Mínimo de } 60 \% \text { - pagamento dos profissionais do } \\
\text { magistério da educação básica em efetivo } \\
\text { exercício; } \\
\text { O restante dos recursos em outras despesas da } \\
\text { educação básica }\end{array}$ \\
\hline $\begin{array}{l}\text { Valor mínimo Nacional } \\
\text { p/aluno }\end{array}$ & $\begin{array}{l}\text { Fixado anualmente com as seguintes } \\
\text { diferenciações: } \\
\text { 1) Até 2004: } 1^{\mathrm{a}} \text { a } 4^{\mathrm{a}} \text { série; } 5^{\mathrm{a}} \\
\text { a } 8^{\mathrm{a}} \text { série; } \\
\text { 2) partir de 2005: séries } \\
\text { iniciais urbanas, séries } \\
\text { iniciais rurais; } 4 \text { séries } \\
\text { finais urbanas; e } 4 \text { séries } \\
\text { finais rurais e educação } \\
\text { especial }\end{array}$ & $\begin{aligned} & \text { Fixado anualmente com as diferenciações: } \\
& \text { 1) } \text { Ed. Infantil (0 a } 3 \text { anos) } \\
& \text { 2) } \text { Ed. Infantil (Pré-escolar) } \\
&3) \text { Séries iniciais urbanas } \\
&4) \text { Séries iniciais rurais } \\
&5) 4 \text { séries finais urbanas } \\
&6) 4 \text { séries finais rurais } \\
&7) \text { Ensino Médio urbano } \\
&8) \text { Ensino Médio rural } \\
&9) \text { E. Médio Profissionalizante } \\
& \text { 10) } \text { EJA } \\
&11) \text { EJA - Profissionalizante } \\
&12) \text { Educação Especial } \\
& \text { 13) Educação Indígena e Quilombola } \\
& \text { Não pode ser inferior ao do último ano do } \\
& \text { FUNDEF }\end{aligned}$ \\
\hline
\end{tabular}


Os dados da Tabela 1 informam que a diferenciação entre o Fundef e a proposta do Fundeb é evidente em várias direções: abrangência para toda educação básica; ampliação do volume de recursos; diferenças nos valores por aluno; ampliação significativa da participação da União, entre outras. Entretanto, a discussão central a ser levantada neste texto é a de saber até que ponto essa nova proposta de fundo indica possibilidades de reduzir as desigualdades educacionais e melhorias na qualidade de ensino.

Obviamente que tanto o primeiro quanto o segundo indicador de análise demandam a ampliação de recursos para a educação básica. Quanto a isso, observa-se a ela estará condicionada à participação da União, que pelo previsto representa valores significativamente superiores à suplementação realizadas ao Fundef, visto que de R\$ 395,3 milhões, em 2005, passaria para $\mathrm{R} \$ 2$ bilhões no primeiro ano de vigência do Fundeb. Por outro lado, está previsto que o número de matrículas será ampliado de 30, 7 milhões para 47,7 milhões, a partir do $4^{\circ}$ ano, ou seja, em 17 milhões.

Por isso, sobre a possibilidade de ampliação dos recursos chama-se atenção para dois pontos apresentados na PEC e que estão interligados. O primeiro diz respeito ao fato de a base da complementação da União ser definida a partir de valores absolutos (moeda corrente) e não em percentuais e pior: sem considerar o valor do custo-aluno qualidade e as necessidades educacionais diferenciadas entre os municípios. O segundo se refere ao estabelecimento do limite da participação da União de no máximo $30 \%$ dos recursos vinculados à manutenção e desenvolvimento do ensino.

O simples olhar, desprovido de parâmetros referenciais, indicaria que a partir do volume de recursos previsto para o novo fundo poderíamos vislumbrar impactos positivos em relação ao combate às desigualdades educacionais intra e inter-regionais e possibilidades de melhorias na qualidade de ensino. Entretanto, ao considerarmos a previsão do número de alunos a ser atendido pelo sistema público e os valores a serem gastos por aluno, as expectativas são compulsoriamente reduzidas.

Um indicador que sustenta este argumento encontra-se no estudo realizado por CASTRO (2003), sobre as necessidades e possibilidades de financiamento da educação. Em simulações realizadas para a constituição do Fundeb, esse autor apresenta diferentes cenários em relação: (i) ao atendimento às matrículas; (ii) às receitas disponíveis; (iii) aos recursos financeiros necessários; (iv) ao gasto mínimo por aluno/ano; (v) às necessidades de financiamento por esfera de governo; (vi) e à complementação de 
recursos entre os governos. Para isso, considerou os anos de 2003, 2006 e 2011 e a subvinculação de $25 \%$ dos impostos estaduais e municipais.

Ainda que a proposta atual do Fundeb tenha excluído os impostos municipais e o percentual vinculado seja gradativo até atingir 20\%, o estudo de CASTRO oferece pistas para pensarmos o que representa a participação da União ao fundo e as possibilidades desta proposta combater as desigualdades educacionais e melhorar a qualidade de ensino.

Segundo o autor, essa possibilidade está condicionada ao valor de gasto mínimo por aluno. Por exemplo, se considerarmos a simulação referente ao ano de 2006 e o cenário mais otimista denominado de Cenário $\mathrm{C}$, que estabelece o gasto aluno/ano em torno de $\mathrm{R} \$ 1.285,00$ - com o qual poderíamos vislumbrar ensino de qualidade -, ocorreria uma situação em que os estados reduziriam significativamente a complementação dos recursos para os municípios e estes a cessariam. Neste caso, a União se responsabilizaria por quase a totalidade das transferências e sua complementação atingiria o valor de 30 bilhões de reais. Segundo o autor, com base nas projeções feitas no referido estudo, os recursos disponíveis pela União não seriam suficientes para garantir todas as complementações necessárias, haja vista que os gastos do MEC com educação têm girado em torno de R 20 bilhões (2002). Ressalta-se: na atual proposta do Fundeb, a complementação da União será de apenas R \$ 4 bilhões no quarto ano de vigência do fundo.

Com base nessas considerações, é possível prever os limites do novo fundo como política promissora no combate às desigualdades educacionais e para melhorar a qualidade de ensino, principalmente considerando a previsão de ampliação das matrículas da educação básica.

Para CASTRO (2003), a aplicação mínima por aluno no patamar de R \$1.285,00 seria sustentável apenas na hipótese de crescimento maior na arrecadação tributária ou de alterações na alocação de recursos, de modo a garantir mais recursos para educação. Como o Fundeb não projeta a ampliação de recursos para a educação, dificilmente esse valor por aluno será alcançado.

Por fim esse autor argumenta:

Por essas simulações observa-se que o FUNDEB só será viável se for grande o envolvimento e compromisso financeiro da União, mediante ampliação dos recursos, principalmente se houver pacto em relação ao aumento da qualidade da educação, o que com certeza envolve um aporte maior de recursos. Chama-se atenção que a complementação da União deve ser suficiente para sustentar os aumentos quantitativos e as exigências qualitativas da educação básica, uma vez que a arrecadação dos 
impostos estaduais e municipais pode não crescer, em termos reais, em proporção maior

que as matrículas (CASTRO, 2003, p.10).

\section{Considerações Finais}

O acompanhamento do processo de elaboração e discussão da proposta de criação do Fundeb tem revelado que questões fundamentais constatadas como impactos negativos do Fundef na educação de estados e municípios brasileiros não têm sido preocupação na definição desse novo fundo.

Com base nos estudos consultados, as questões fundamentais residem nas constatações de que: (i) o Fundef vem contribuindo para ampliar as desigualdades educacionais inter-regionais, mediante o aumento da diferença entre os maiores e menores per capita; (ii) a qualidade do ensino continua sendo comprometida pelo fato de as responsabilidades pelo atendimento às matrículas terem sido repassadas para os municípios sem que fossem analisadas as condições financeiras dos mesmos; (iii) comprometimento do atendimento à educação infantil, ainda assim as matrículas em creches estavam sendo excluídas e só passaram a ser incluídas recentemente à proposta em função de muita pressão exercida por representantes de entidades governamentais e não-governamentais (Campanha Nacional pelo Direito à Educação; Conselho Nacional dos Direitos da Criança e do Adolescente; MIEIB; OMEP/Brasil, entre outros). Esperase que a inclusão das matrículas em creches não seja derrubada nas discussões no Senado. Os estudos que avaliam o Fundef indicam que o combate às desigualdades educacionais e as possibilidades de melhoria da qualidade do ensino demandam fundamentalmente a ampliação de recursos para educação.

Nessa perspectiva, a proposta de criação do Fundeb tem evidenciado que a lógica norteadora da constituição desse fundo continua sendo a mesma do Fundef, qual seja: os recursos financeiros destinados à educação são suficientes para combater as desigualdades educacionais e para melhorar a qualidade de ensino e que o problema reside no gerenciamento e distribuição dos recursos.

Diante disso, concluímos que considerando a questão central que vem subsidiando as disputas em torno da configuração do novo fundo - contingenciamento de recursos da parte da União e perdas e ganhos financeiros da parte dos estados e municípios, dificilmente os impactos do novo fundo serão promissores em relação ao combate às desigualdades educacionais e as possibilidades de melhorar a qualidade da educação. 
Desta feita, parece-nos que a relação entre a produção de conhecimentos sobre o financiamento da educação e a definição de novas políticas para a área continua tênue, frágil ou inexistente, pois a questão central são as possibilidades de perdas e ganhos e não necessariamente o combate às desigualdades educacionais e a melhoria na qualidade de ensino no País.

\section{Referencias Bibliográficas}

BASSI, M. E. Gestão e financiamento da educação básica. 2001.Tese (Doutorado em Educação). Pontifícia Universidade Católica de São Paulo. São Paulo, 2001.

BRASIL, Lei $\mathrm{n}^{\circ}$ 9424, de 24 de dezembro de 1996. Dispõe sobre o Fundo de Manutenção e Desenvolvimento do Ensino Fundamental e de Valorização do Magistério. Publicada no D.O.U 250, de 26/12/1996.

BRASIL, Emenda Constitucional $\mathrm{n}^{\circ}$ 14, de 12 de setembro de 1996. Modifica os arts. 34, 208, 211 e 212 da Constituição Federal, e dá nova redação ao art. 60 do Ato das Disposições Constitucionais Transitórias. Publicada no D.O.U 179, de 13/09/1996.

BRASIL, Decreto no 2.264, de 27 de junho de 1997. Regulamenta a Lei $\mathrm{n}^{\circ}$ 9.424/96, no âmbito federal e determina outras providências. Publicada no D.O.U, de 27/06/1997.

CASTRO, J.A. Financiamento da educação: necessidades e possibilidades de financiamento. IPEA, Diretoria de Estudos Sociais, 2003 (mimeo).

CASTRO, M. H. G. As desigualdades regionais no sistema educacional brasileiro. Texto apresentado no seminário Desigualdades e Pobreza no Brasil, Rio de Janeiro, 1999.

GEMAQUE, R. M. O. (2004). Financiamento da Educação - O FUNDEF na Educação do Estado do Pará: Feitos e Fetiches. Tese de Doutorado, Faculdade de Educação da Universidade do Estado de São Paulo, 2004.

MELCHIOR, J. C. A. Mudanças no Financiamento da Educação no Brasil. Col. polêmicas do nosso tempo; v. 57.Campinas, SP: Autores Associados, 1997.

MINISTÉRIO da Educação e do Desporto -MEC. Estudo sobre o valor do FUNDEF. Relatório Final do Grupo de Trabalho, Brasília, 25 de março de 2003. Disponível em: $<$ http://www.inep.gov.br $>$. Acesso em agosto de 2003.

MINISTÉRIO da Educação e do Desporto -MEC. Proposta de Emenda Constitucional n 536-A, de 1997. Disponível em: < http://www.mec.gov.br $>$. Acesso em janeiro de 2006.

MINISTÉRIO da Educação e do Desporto -MEC. Proposta de Emenda Constitucional n $415 / 05$, de novembro de 2005 ( $2^{\text {a }}$ versão). Disponível em: < http://www.mec.gov.br>. Acesso em janeiro de 2006

MINISTÉRIO da Fazenda. Secretaria do Tesouro Nacional. Boletim-Ano V, $\mathrm{n}^{\circ}$ 08agosto/2002.

PARTIDO DOS TRABALHADORES. Programa de Governo. Uma escola do tamanho do Brasil. Disponível em:www.pt.org.br - acesso em março de 2003 
SOUZA JR., L. Financiamento e Educação. Os impactos do FUNDEF na Educação Básica da Paraíba. 2003.Tese (Doutorado em Educação). Faculdade de Educação, Universidade de São Paulo, São Paulo, 2003.

VERHINE, R.; ROSA, D. FUNDEF no Estado da Bahia. Gestão em Ação, Bahia, V.6,n' 2 , p.107-117, 2003. 